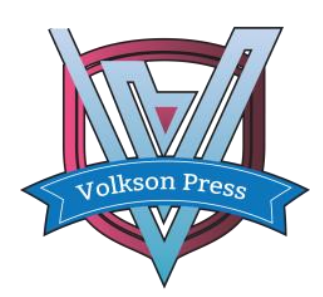

Contents List available at VOLKSON PRESS

Economics \& Management Innovations(EMI)

DOI : http://doi.org/10.26480/icemi.01.2017.273.275

\title{
A Proposed Framework for a Water-Energy Nexus in Water Treatment Plants
}

\author{
Denchai Maneenoon ${ }^{1, *}$, Aumnad Phdungsilp ${ }^{1}$, Suparatchai Vorarat ${ }^{1}$, Natapat Areerakulkan ${ }^{1}$

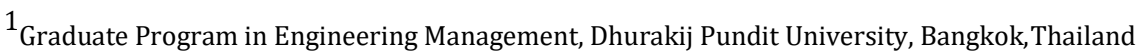 \\ *email: dchmanee@gmail.com
}

This is an open access article distributed under the Creative Commons Attribution License, which permits unrestricted use, distribution, and reproduction in any medium, provided the original work is properly cited.

\section{ARTICLE DETAILS}

\section{Article History:}

Received 02 october 2017

Accepted 06 october 2017

Available online 11 october 2017

Keywords:

Water-Energy Nexus (WEN), Water treatment systems, Waterworks, Optimization..

\section{ABSTRACT}

Energy and water are interlinking each other, especially in the water treatment systems. Energy is mainly used to operate the water treatment plant and to improve the water quality, including water transferring, water pumping, chemical feeding, clarifying, and filtering. The significant challenges of the waterworks authorities are how to produce efficiently and economically water supply and how to manage the limited resources like water and energy resources. The Water-Energy Nexus (WEN) is an integrated concept that considers both energy and water resources in a holistic perspective, so that it can manage the challenges in the optimal way. However, there are some research gaps in the literature. The existing body of knowledge cannot apply to study and analyze the WEN in a water treatment plant. This study aims to study and propose the WEN framework that can improve the performance of the water treatment system. The conceptual model of WEN in water treatment system can be evaluated in terms of the energy and economic performances. The developed WEN framework in this paper will be applied to a case study in Bangkok, Thailand for performance evaluation under different scenarios.

\section{Introduction}

The water supply is an important infrastructure of many activities, such as households, industrial activities, and services sector. Nowadays, the demand for high quality water is increasing. Water utilities need to provide water to meet the demand, as well as to support water-related activities. Most of the water authorities are facing many problems that affect to the quality and quantity of water, for instance water contamination, drought, and flooding. Accordingly, the authorities have to provide water resources that adequate to consumers and to improve the water quality following the national and international water standard, such as World Health Organization (WHO). To improve the quality of water, related water authorities require more resources and lead to extra expenses, for example chemical cost and electrical cost. In addition, these expenses are more increases when an operation is facing to drought or flooding. So, the main challenge is how to produce effectively and economically water supply to the users.

The energy sector is also important to many economic sectors. Energy sector needs the water to produce the fuels, for example mining, extracting, and transportation. According to the fuel production, it can illustrate the interrelation between the water and energy. It is generally accepted that energy resources are limited because of the depletion of fossil fuels and the increasing of energy demand for economic activities. The inefficient use of energy should also be counted to the challenge of optimal water supply production. On the other hand, the water sector requires energy for its operation. Technically, this interconnection is socalled Water-Energy Nexus (WEN).

Recently, the WEN is a growing research area in the literature. There is existing WEN framework based on the integrated conservation concept that considers the interrelationship between water resources, energy resources, and climate change. Understanding these relationships, it would support to analyze the interlinkage between the systems (water system, energy system, and climate system) and how each system affects other systems.

The aforementioned background leads to the need for studying the interrelationship between raw water and energy in the water treatment systems. It can be enhanced to realize the problems and limitations of these two systems (water and energy systems). The understanding of the
WEN would provide the solutions to improve the performances of the systems. These performances can be shown in terms of energy performance and economic performance which are the results from improving the performance of water system.

In the literature, most studies cannot directly apply to analyze the WEN in the context of water treatment system. Moreover, the knowledge of WEN in the water treatment system is not well enough. This paper contributes to fill the research gaps by developing the WEN framework for analyzing the water treatment system in particular. Moreover, the proposed framework will be applied to study and evaluate the performances of the water treatment system in the future. This paper is organized into five sections. Section 2 presents a review of existing WEN framework. Section 3 describes the study method. Section 4 presents the proposed framework of the WEN in water treatment system. The implementation of the proposed framework and conclusion are dealt in section 5 with discussion on a future work.

\section{Review of Existing WEN Framework}

In the literature, the interlinkage between water system and energy system is so-called WEN. This word was originally mentioned by Gleick in the 1990s [1]. Figure 1 illustrates the WEN diagram that presents the water and energy relationship. According to Figure 1, the lower half part of that diagram can be shown that water is important to energy conversion processes. For mining and extracting mineral of fuel production, water is the necessary resource that uses in these processes. Water is also considerable importance for biogas production and steam turbine electricity generation. Hydropower is a good example to present the interlinkage of water for energy. Water stream uses to drive turbine for converting mechanical energy to electrical energy. Recently, thermoelectric cooling is one of interesting renewable energy technologies. Water is also use in the thermoelectric cooling process. However, the fossil fuel energy conversion processes are emitted $\mathrm{CO} 2$ emissions and these emissions must be reduced from the energy sector. Some emission control method requires the water to reduce the emissions. It can be said that water is an important factor to the energy sector and it is used in the most of energy conversion processes.

According to the upper part of WEN diagram in Figure 1, it is important to use energy in most of the water treatment processes, especially in the 
water supply treatment. The raw water is pumped by the pumps. Then, it needs to improve the water quality by many processes, such as desalination, coagulation, clarification, and filtration. These processes need chemical feeding and electrical energy to the processes. Then, the water is distributed to the customers. In some cases, the water is transferred to transmission method and storage in the sub pumping stations before distributed to the customers. It can be seen that energy and water are interlinked each other in the water treatment system. Energy needs to improve the water quantity and quality in chemical feeding, system operation, and distribution to the households and industries

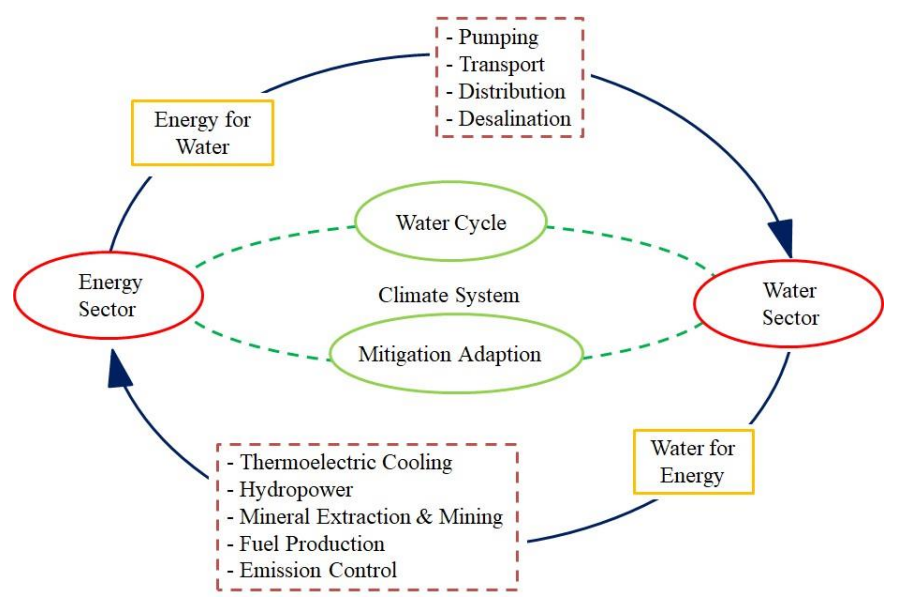

Figure 1. WEN diagram (Adapted from [5]).

In existing studies, there are many studies concerning the WEN. Cuiping and Qiang [2] reviewed the literature on energy dependence on water in terms of energy type, and the objective is finding the gaps in the current literature. The interesting finding is the insufficient of the classification degree of the value chain of energy. Mostly, water consumption of the whole life cycle of the energy systems or several kinds of energy is studied, while few studies divide the chain into extraction, processing, and conversion. Moreover, the studying on the cleaning, transportation, and utilization phases are still lacking.

Larry et al. [3] used WEAP (Water Evaluation and Planning System) and LEAP (Long-range Energy Alternative Planning system), the popular planning tools for water system and energy system, to analyze the impact of climate change on water and energy systems in Sacramento, California. The interesting issue is using these models to find water characteristics that are needed to project the energy demand, for example energy for pumping groundwater by urban and agricultural users and energy for treating largely by the urban water district. The results from climate simulation show that the electricity imports to the area would increase during the hot period when the power production is constrained.

Aurelie et al. [4] proposed model to access an optimal water-energy modeling for water reuse and non-conventional water use in the waterscarce Middle East region. TIAM-FR (TIMES Integrated Assessment Model France) energy model was used in this study. The TIAM-FR model has linkage procedure between water energy systems. There are mainly two systems considered in this research, TIAM-FR energy system model and TIAM-FR water system model. TIAM-FR energy system model analyzes the energy demand that shows the result of energy for water. Moreover, this system model can be the inputs of TIAM-FR climate module that illustrates greenhouse gas, temperature, and atmosphere radiative forcing. The data of energy for water is the inputs to the TIAM-FR water system model that shows the water demand. The results show that electricity demand can be underestimated approximately $40 \%$ when the additional demand for electricity induced by water needs is not considered. The energy-intensity of water is a useful method for analyzing the nexus according to technical strategies and water management options.

Mohammed [5] studied to quantify the effects of some key operational economic and region specific gas consumption features on the gas requirements in the power and water sectors. The Emirates of Abu Dhabi is used as a case study. The interesting approach is using multilevel Divisia Index Approach (LMDI type I) to access past contribution of identified factors to the total fuel consumption in the electricity and water sectors in the 1999-2010 period, and the energy intensity effect shows the efficiency of electricity consumption use.

William and Amro [6] developed an engineering system model of the energy-water nexus. This system model created form bond graph representations of descriptive System Modeling Language (SysML) functions that can develop water supply and wastewater systems. The study used physics- based models and increased scope to improve on existing approach. The advantages of a transport physics-based energywater nexus model can contribute to a practical industrial application. At the smallest scale, the merits of competing for water and energy technologies can be assessed not only the costs or their industrial impacts, but also their impacts within the energy-water nexus as a system.

There are significant studies concerned about the WEN, particularly in the way of energy for water. Feng and Chen [7] developed an energy-water nexus conceptual framework. It is focused on the energy used for the wastewater extraction, the operation of the wastewater treatment process, and the wastewater recycling. They also examined the concept of the efficiency and redundancy of wastewater treatment by structural nexus analysis based on Network Environ Analysis (ENA) approach. Tomoshiro et al. [8] developed a methodology for estimating water demand and water pollutants. The model of water demand and water pollutant discharges of industries is based on a regional Input-Output analysis. According to the methodology in this paper, it can be applied to the WEN in water treatment system.

For the performance evaluation, Wang and Xia [9] proposed the Building Retrofitted Facilities Corrective Maintenance Planning (BRFCMP). The BRPCMP problem is a multi-objective problem. The performance measures are energy performance and economic performance. These performance indicators could be adapted to use in the WEN framework. The WEN in water supply system was done the Bangkok, Thailand [10]. The energy use in the water supply system of the Metropolitan Waterworks Authority (MWA) was evaluated. The results showed that the total energy use by MWA's water supply system is $0.2338 \mathrm{kWh} / \mathrm{m} 3$. The energy utilization in the water transmission, water distribution, water treatment, and raw water intake is $41 \%, 35 \%, 20 \%$, and $4 \%$, respectively.

Somsak [11] studied the crisis problems in the water treatment process of MWA. The results found that there is crisis related to the raw water sources, such as water contamination and water quality, and the crisis is affected to water quality, water quantity, operation cost, and the image of MWA. The researcher suggested that the solutions should be solving the problem of raw water sources and solving the problem in the water treatment process. According to the previous studies, there are some research gaps in the literature. It can be said that the existing knowledge from the literature cannot apply to analyze the WEN in particular in the water treatment system. Therefore, the ultimate aim of this paper is to propose the WEN framework that can be applied to the real case study later on.

\section{Study Method}

The study method used in this paper is shown in Figure 2. First, the literature review and investigation of water treatment is carried out by means of scientific databases and site visits. The literature review is focused on theoretical perspective, conceptual model, and previous research articles in the area of WEN. To understand how the water treatment plant works, it is also important to investigate the water treatment process. Second, the input data are set by the previous step. These data are energy consumption, water quality, raw water quantity, water supply quantity, and chemical demand. Next, the input data are analyzed by Input-Output analysis approach to find the relationship of WEN, energy performance, economic performance, and the weakness of the water treatment system. Then, the variables from the previous step are compared and simulated through different cases, such as the business-as-usual (BAU), the limited budget, and the modified system. Finally, it can propose the solution to improve and create the effective water treatment system. 


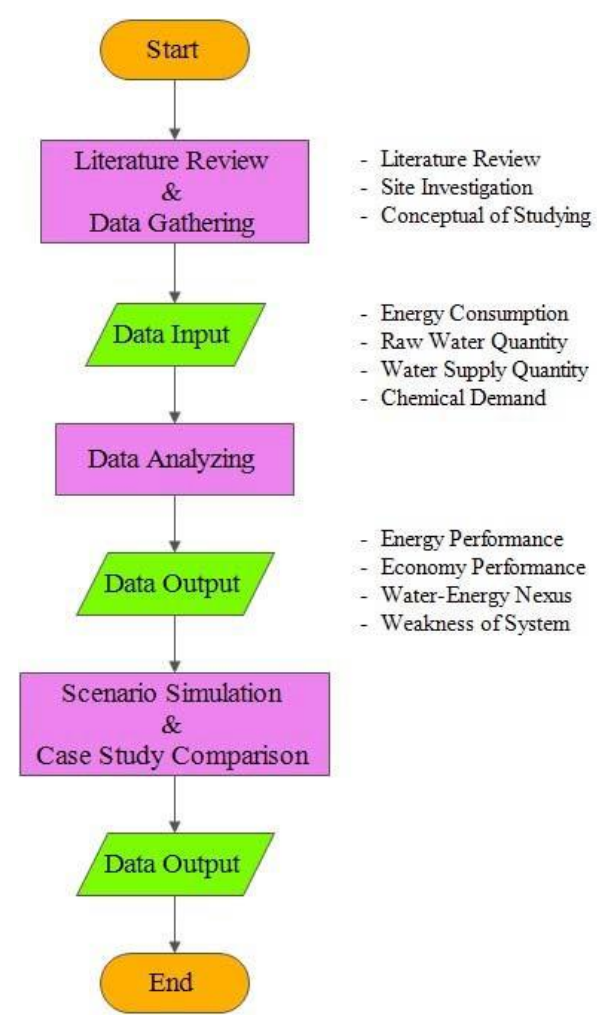

\section{Proposed Framework}

The system boundary in the conceptual model of this study is shown in Figure 3. There are four main systems, namely raw water pumping station, solid system clarifier, filter tank, and filtered water reservoir. The desired inputs are raw waters quality and quantity, electrical energy demand, and the amount of chemical feeding. The expected outputs are water supply quality and quantity. The electrical energy is used in the raw water pumping system and the transferred water to the treatment system. The blower pump and wash water pump are used to support the filter system. Finally, the filtered water is transferred to the reservoir before sending to the transmission system and the distribution system. Moreover, the chemical feeding is also important in the water treatment system. Lime, coagulant, chlorine, and alum are fed between the raw water pumping station and solid clarification. They are also fed in the reservoir to disinfect and equalize the water. The water treatment reveals the interrelationship between water and energy, and it should be considered in WEN scheme to improve the performance of this system.

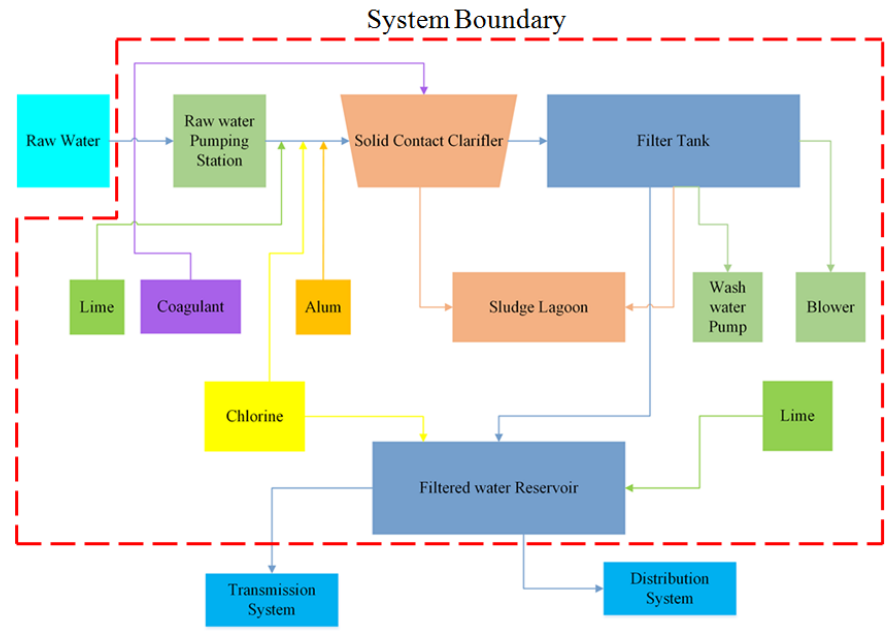

Figure 3. Proposed conceptual model of the WEN in water treatment system

\section{Towards Implementation of the Proposed Framework and} Conclusion

The proposed framework is considered the terms of input parameters and outputs. This framework can be analyzed by means of the Input-Output analysis approach. The proposed framework will be studied and evaluated the water supply treatment system using a case study in Bangkok. The energy performance, economic performance, and weakness of the system in the context of WEN will be evaluated. It is expected that findings from this work would contribute to improve the water treatment system. The study will focus on scenarios simulation and compare the effectiveness of different cases. The performance of the system will be simulated in various cases, namely BAU, limited budget, and modified system. In addition, the work will be made an attempt to compare the performances of different cases. Finally, it is expected that the proposed WEN framework would provide solutions to effectively improve the water treatment system.

\section{References}

[1] P.H. Gleick: Water and Energy. Annual Review of Energy and the Environment, 19, P. 267- 299. (1994).

[2] T. Cuping and Z. Qiang: The Energy-Water Nexus: A Literature Review of the Dependence of Energy on Water, Energy Procedia, 88, P. 277-284. (2016).

[3] L.D. Larry et al.: An Integrated Assessment of Water-Energy and Climate Change in Sacramento, California: How Strong is the Nexus?, Climate Change, 132, P. 223-225. (2015).

[4] D. Aurelie et al.: Water Modeling in and Energy Optimizaiton Framework-The Water-scarce middle east context, Applied Energy, 101, P. 268-279. (2013).

[5] K. Mohammed: Fuel Consumption Efficiency for Electricity and Water Production in Abu Dhabi, Energy Strategy Reviews, 13-14, P. 109-114. (2016).

[6] N.L. William and M.F. Amro: Quantitative Engineering Systems Modeling and Analysis of the Energy-Water Nexus, Applied Energy, 135, P. 142-157. (2014).

[7] L. Feng and B. Chen: Energy-Water Nexus of Wastewater Treatment System: Conceptual Model and Framework. Energy Procedia, 104, P.141145. (2016)

[8] 0. Tomoshiro et al.: Analysis of Water Demand and Water Pollutant Discharge Using A Regional Input-Output table: An Application to the City of Chengqing, Upstream of the Three Gorges Dam in China, Ecologi and Economics, 58, P. 221-237. (2006).

[9] B. Wang and X. Xia: Optimal Maintenance Planning for Building Energy Efficiency Retrofitting form Optimization and Control System Perspectives. Energy and Building, 96, P. 299 - 208. (2015).

[10] S. Babel Mukand and A. Kanchanapun: Water-Energy Nexus: an Analysis of the Bangkok Water Supply System, Thailand. 3G IWRM Conference, 22 November 2012.

[11] P. Somsak: Crisis Education and Solutions to the Crisis Problems in Water Treatment Process of MWA. National Defense Studies Institute, Thailand. (2015). 